Research Paper

\title{
Clinicopathological and lleocolonoscopic Characteristics in Patients with Nodular Lymphoid Hyperplasia in the Terminal Ileum
}

\author{
Ritian Lin ${ }^{1}$, Huiying $\mathrm{Lu}^{1}$, Guangxi Zhou ${ }^{1}$, Qing Wei², Zhanju Liu ${ }^{1 凶}$ \\ 1. Department of Gastroenterology, the Shanghai Tenth People's Hospital of Tongii University, Shanghai 200072, China; \\ 2. Department of Pathology, the Shanghai Tenth People's Hospital of Tongji University, Shanghai 200072, China. \\ $\triangle$ Corresponding author: Dr. Zhanju Liu, Department of Gastroenterology, the Shanghai Tenth People's Hospital, Tongji University, Shanghai 200072, China. \\ Email: liuzhanju88@126.com Tel: 86-21-66301164 Fax: 86-21-66303983 \\ (c) Ivyspring International Publisher. This is an open access article distributed under the terms of the Creative Commons Attribution (CC BY-NC) license \\ (https://creativecommons.org/licenses/by-nc/4.0/). See http://ivyspring.com/terms for full terms and conditions.
}

Received: 2017.02.04; Accepted: 2017.06.17; Published: 2017.07.18

\begin{abstract}
Nodular lymphoid hyperplasia (NLH) in the small intestine is a rare benign lesion, characterized by the presence of multiple small nodules on the surface of the intestine. To define the clinicopathological and colonoscopic characteristics in Chinese patients with ileal NLH, we collected 65 patients with NLH in the terminal ileum from the endoscopic database in our hospital and clinical data from medical records. Histology and immunohistochemical staining were performed in the biopsies. The results demonstrated that the main symptoms included diarrhea (70.8\%), abdominal pain (60.0\%), hematochezia (46.2\%), anemia (40.0\%), and hypoproteinemia (21.5\%). Enteroscopy revealed multiple, sporadic, granular or round-shaped nodules with diameters between 2 and $5 \mathrm{~mm}$ in the terminal ileum. The histology revealed the nodules consisted of mass lymphoid follicles in the lamina propria and submucosa of the terminal ileum. The follicles contained mitotically active germinal centers surrounded by well-defined lymphocyte mantles and composed predominantly of $\mathrm{CD}_{2} \mathrm{O}^{+} \mathrm{B}$ cells. The diseases found in patients with $\mathrm{NLH}$ included chronic diarrhea, Crohn's disease, ischemic enterocolitis and allergic purpura. The level of hemoglobin in NLH patients who had diarrhea and hematochezia remarkably decreased as compared with those in patients with chronic diarrhea. In conclusion, ileocolonoscopic screening is an important step to find the NLH in terminal ileum patients with diarrhea, abdominal pain, hematochezia, and hypoproteinemia. Histological examination is necessary for the exclusion of malignancy and chronic inflammation.
\end{abstract}

Key words: Abdominal pain, Anemia, Diarrhea, Hematochezia, Lymphoid follicles, Nodular lymphoid hyperplasia.

\section{Introduction}

Nodular lymphoid hyperplasia (NLH) in the small intestine is a rare benign lesion, which is characterized by the presence of multiple small nodules on the surface of the intestine. The nodules are found to be present in the lamina propria and superficial submucosa of the intestine [1]. Its diagnosis is mainly based on endoscopic and histological examination, which is markedly hyperplastic lymphoid follicles, mitotically active germinal centers with well-defined lymphocytic mantles [2]. The pathogenesis of NLH remains unclear, but there is a hypothesis associated with immunodeficiency. It may originate from proliferative plasma cell precursors for a maturational defect in the development of B lymphocytes [3]. Evidence has shown that NLH may be associated with a risk factor for intestinal lymphoma [4]. It can manifest an asymptomatic disease or gastrointestinal symptoms like diffuse abdominal pain, chronic diarrhea, and bleeding [5]. Since the endoscopic manifestations are 
remarkably similar to polyposis, the disease is easy to be misdiagnosed [6]. The previous literature mainly included case reports and a fraction of patients [7-9]; it has been reported in patients with human immunodeficiency virus infection, common variable immunodeficiency (CVID), Giardia lamblia infection, helicobacter pylori (Hp) infection, familial adenomatous polyposis, and Gardner's syndrome [10].

In this study, we retrospectively analyzed the clinicopathological characteristics and ileocolonoscopic findings of 65 Chinese patients with NLH in the terminal ileum. Individuals have diarrhea, abdominal pain, and hematochezia, the ileocolonoscopic screening and histological examination seem to be warranted to have a differentiating diagnosis for NLH.

\section{Materials and Methods}

\section{Patients and sample collection}

From January 2010 to December 2015, we collected 65 patients who underwent enteroscopy showing NLH in the terminal ileum from the endoscopic database at the Department of Gastroenterology, the Shanghai Tenth People's Hospital affiliated to Tongji University (Shanghai, China). There were 65 patients (46 males, 19 females; aged 11-73 years) with diarrhea, abdominal pain, hematochezia or hypoproteinemia. The endoscopic images were reviewed and confirmed by the endoscopic team. NLH was diagnosed by the results of endoscopy and histopathology. The biopsies were also taken at the site of the nodular hyperplasia of the terminal ileum for further histological analysis.

\section{Clinical and laboratory data}

The detailed clinical data were collected from 65 patients, including age, gender, types of symptoms, and accompanying diseases. Laboratory tests included hemoglobin, serum total proteins, albumin, immunoglobulin, C-reactive protein (CRP), alkaline phosphatase (ALP), erythrocyte sedimentation rate (ESR), white blood cell counts (WBC), fecal occult blood test, classification of fecal bacteria, virus, and parasites. Determination of hemoglobin, serum total proteins, albumin, immunoglobulin, CRP, ALP, ESR, and $\mathrm{WBC}$ was performed according to routine laboratory tests (Beckman; Brea, CA, USA).

\section{Histology and immunohistochemistry}

Ileal biopsies were taken from all patients during the endoscopic examination for histological and immunohistochemical analysis. Samples of intestinal biopsy were performed by routine hematoxylin-eosin staining. Immunohistochemical staining was done on
5 - $\mu$ m-thick paraffin-embedded tissue sections. The sections were dewaxed in xylene and rehydrated in graded ethanol. The antigen retrieval was done by microwave heating for 20 minutes at $98{ }^{\circ} \mathrm{C}$. Endogenous peroxidase was blocked by immersing the sections in $3 \% \mathrm{H}_{2} \mathrm{O}_{2}$ for 15 minutes, these sections were subsequently incubated with rat anti-human CD3 mAb (Cell Signaling Technology; Shanghai, China) at a dilution of $1: 200$ at $4{ }^{\circ} \mathrm{C}$ overnight. After washing, the sections were then incubated for 30 minutes with biotinylated secondary rabbit anti-rat IgG antibody (Cell Signaling Technology) at a dilution of 1:400 at room temperature. The color reaction product was developed using 3,3-diaminobenzidine (Cell Signaling Technology), and sections were counterstained with hematoxylin. Immunohistochemical staining for CD5, CD10, CD20, CD79a, $\mathrm{Ki}-67$, and Bcl-2 was also performed using the same dilution and technique as described above.

\section{Statistical analysis}

All data were expressed as absolute and/or relative frequencies, and mean \pm standard deviation (SD). Statistical significance was calculated by Kruskal-Wallis test. SPSS version 20.0 software (SPSS, Chicago, IL, USA) was used. A $p$ value $<0.05$ was considered statistically significant.

\section{Ethics approval}

The study was reviewed and approved by the Hospital and University Review Committees for Medical Research.

\section{Results}

\section{Clinical data}

Of all 65 patients with NLH in the terminal ileum, 46 were men and 19 were women. The mean age of the patients was 31.92 years, ranged 11-73 years. Diarrhea was the cardinal symptom in 46 $(70.8 \%)$ patients, and abdominal pain was the subordinate symptom in $39(60.0 \%)$ patients. Thirty patients $(46.2 \%)$ had hematochezia, and 26 patients $(40.0 \%)$ had anemia. Hypoproteinemia was found in 14 patients (21.5\%), and 13 patients $(20.0 \%)$ had nausea and vomiting. However, only 5 patients $(7.7 \%)$ had a marked loss of body weight (the average value of weight loss was $4.4 \mathrm{~kg}$, and lasted for a month) (Table 1).

Hemoglobin was found to range from 50 to 153 $\mathrm{g} / \mathrm{L}(116.67 \pm 24.44 \mathrm{~g} / \mathrm{L})$ in all patients. In 26 patients with anemia, 17 patients had mild anemia (with $\mathrm{Hb}$ from $90 \mathrm{~g} / \mathrm{L}$ to the lower range limit of $120 \mathrm{~g} / \mathrm{L}$ in non-pregnant women or $130 \mathrm{~g} / \mathrm{L}$ in men), 5 had moderate anemia $(60-89 \mathrm{~g} / \mathrm{L})$, and the rest of 4 
patients had severe anemia $(30-59 \mathrm{~g} / \mathrm{L})$. Serum albumin was found to range from 24 to $44 \mathrm{~g} / \mathrm{L}$ (35.94 $\pm 5.49 \mathrm{~g} / \mathrm{L}$ ), while serum total proteins ranged from 49 to $80 \mathrm{~g} / \mathrm{L}(65.69 \pm 8.59 \mathrm{~g} / \mathrm{L})$ (Table 2). Otherwise, the stool specimens of patients were also examined and found to be negative for pathogenic bacteria, virus, parasites, and ova. Hemoglobin in patients who had diarrhea accompanied by hematochezia was statistically significantly lower compared with that in patients with diarrhea who had no hematochezia $(86.82 \pm 18.91 \mathrm{~g} / \mathrm{L}$ vs $129.71 \pm 12.39 \mathrm{~g} / \mathrm{L}, p<0.01)$. The level of hemoglobin was found to be obviously decreased in patients who had hematochezia but no diarrhea compared with that in patients who had diarrhea but no hematochezia (109.89 $\pm 26.66 \mathrm{~g} / \mathrm{L}$ vs $129.71 \pm 12.39 \mathrm{~g} / \mathrm{L}, p<0.01)$. Moreover, patients with diarrhea accompanied by hematochezia had lower hemoglobin than those with hematochezia but no diarrhea $(86.82 \pm 18.91 \mathrm{~g} / \mathrm{L}$ vs $109.89 \pm 26.66 \mathrm{~g} / \mathrm{L}, p<$ $0.05)$. There were no statistical differences in serum total protein and albumin between the groups (Table $3)$.

Table 1. Symptoms of patients with NLH

\begin{tabular}{ll}
\hline Symptoms & $\mathrm{N}(\%)$ \\
\hline Diarrhea & $46(70.8 \%)$ \\
Abdominal pain & $39(60.0 \%)$ \\
Hematochezia & $30(46.2 \%)$ \\
Anemia & $26(40.0 \%)$ \\
Hypoproteinemia & $14(21.5 \%)$ \\
Nausea and vomiting & $13(20.0 \%)$ \\
Weight loss & $5(7.7 \%)$ \\
\hline
\end{tabular}

Table 2. Parameters of biochemical tests in all patients

\begin{tabular}{ll}
\hline Parameters & Values $($ Mean $\pm \mathrm{SD})$ \\
\hline Hemoglobin $(\mathrm{Hb}, \mathrm{g} / \mathrm{L})$ & $116.66 \pm 24.44$ \\
Serum total protein $(\mathrm{g} / \mathrm{L})$ & $65.69 \pm 8.59$ \\
Serum albumin $(\mathrm{g} / \mathrm{L})$ & $35.94 \pm 5.49$ \\
Serum total IgG $(\mathrm{g} / \mathrm{L})$ & $11.30 \pm 2.56$ \\
Serum total Ig A $(\mathrm{g} / \mathrm{L})$ & $1.49 \pm 0.39$ \\
CRP $(\mathrm{mg} / \mathrm{L})$ & $12.32 \pm 15.87$ \\
ALP $(\mathrm{U} / \mathrm{L})$ & $118.38 \pm 85.79$ \\
ESR $(\mathrm{mm} / \mathrm{h})$ & $24.75 \pm 18.51$ \\
WBC $\left(\times 10^{9} / \mathrm{L}\right)$ & $7.69 \pm 3.05$ \\
\hline
\end{tabular}

Table 3. Values of hemoglobin, serum total protein, and albumin in different groups

\begin{tabular}{lrlll}
\hline Groups & $\mathrm{n}$ & $\begin{array}{l}\text { Hemoglobin } \\
(\mathrm{g} / \mathrm{L})\end{array}$ & $\begin{array}{l}\text { Serum total } \\
\text { protein } \\
(\mathrm{g} / \mathrm{L})\end{array}$ & $\begin{array}{l}\text { Serum } \\
\text { albumin } \\
(\mathrm{g} / \mathrm{L})\end{array}$ \\
\hline $\begin{array}{l}\text { Diarrhea with } \\
\text { hematochezia }\end{array}$ & 11 & $\begin{array}{l}86.82 \pm \\
18.91^{*+}\end{array}$ & $61.73 \pm 7.39$ & $33.18 \pm 6.55$ \\
$\begin{array}{l}\text { Diarrhea without } \\
\text { hematochezia }\end{array}$ & 35 & $129.71 \pm 12.39$ & $65.51 \pm 9.05$ & $35.54 \pm 5.19$ \\
$\begin{array}{l}\text { Hematochezia without } \\
\text { diarrhea }\end{array}$ & 19 & $109.89 \pm$ & $66.32 \pm 7.77$ & $38.26 \pm 4.65$ \\
\hline $\begin{array}{l}\text { Kruskal-Wallis test, }{ }^{*} p<0.01 \text { versus diarrhea without hematochezia. }{ }^{+} p<0.05 \text { versus } \\
\text { hematochezia without diarrhea. }\end{array}$
\end{tabular}

\section{Endoscopic findings}

Ileocolonoscopy revealed multiple, sporadic, granular, round-shaped nodules with diameters between 2 and $5 \mathrm{~mm}$ in the terminal ileum (Figure 1A). In addition, ileocolonoscopy also showed nodules, which were tufted or sheet-shaped distribution around the intestinal wall, caused the bowel wall thickening obviously and luminal narrowing (Figure 1B). No anomaly was seen in other parts of small and large intestinal mucosa of idiopathic NLH patients and the hybrid allergic purpura patient. Moreover, six patients with colonic Crohn's disease were found to have superficial ulcers and mucosal erythema in the colon. The gastroduodenoscopy of $\mathrm{Hp}$ infection patient revealed duodenal ulcers. Colonic polyps and hamartomas were observed in one patient with Peutz-Jeghers syndrome. Colonic mucous membrane showed congestion, edema, erosion, scattered small ulcers and disappearance of vessels in the ischemic enterocolitis cases.

\section{Accompanying diseases}

We observed that 15 patients had chronic diarrhea, the main symptoms were diarrhea and abdominal pain. In this group, one had type I diabetes mellitus, and biochemical parameters (e.g. hemoglobin, serum total proteins, albumin, immunoglobulin) and microbiota analysis in the stool (e.g., pathogenic bacteria, virus, and parasites) were all normal. Six patients had colonic Crohn's disease, including 4 patients with remission and 2 in active phase (CDAI equals 174 and 186, respectively). Patients with colonic Crohn's disease were young, and the mean age was 23.83 years old. Two patients in active colonic Crohn's disease presented abdominal pain and diarrhea as a predominant symptom. Only 1 patient at the active stage of Crohn's disease had weight loss. Ischemic enterocolitis was found in 2 cases, and 1 had mild anemia ( $\mathrm{Hb} 108 \mathrm{~g} / \mathrm{L}$ ), hypoproteinemia (serum total protein $50 \mathrm{~g} / \mathrm{L}$, albumin $24 \mathrm{~g} / \mathrm{L}$ ), diarrhea and hematochezia. There was only 1 hybrid allergic purpura patient with diarrhea, abdominal pain, and hypoproteinemia. A patient had mild anemia ( $\mathrm{Hb} 109 \mathrm{~g} / \mathrm{L}$ ) and $\mathrm{Hp}$ infection, whose gastroduodenoscopy revealed duodenal ulcers. Additionally, a patient had abdominal neoplasms, and histological examination demonstrated to be poorly-differentiated adenocarcinoma with widespread metastases. We observed NLH in the terminal ileum was associated with hypogammaglobulinemia (IgG $4.75 \mathrm{~g} / \mathrm{L}$, IgA $0.59 \mathrm{~g} / \mathrm{L})$ in 1 patient who had moderate anemia $(\mathrm{Hb} 78$ $\mathrm{g} / \mathrm{L}$ ). A patient with small intestinal stromal tumor had hypertension, congenital atrial septal defect, and 
severe anemia. Another patient with Peutz-Jeghers syndrome had mild anemia $(\mathrm{Hb} 95 \mathrm{~g} / \mathrm{L})$ (Table 4). The rest of 36 patients had no any concomitant disorder.

Table 4. Accompanying diseases present in patients with NLH

\begin{tabular}{ll}
\hline Diseases & N \\
\hline Chronic diarrhea & 15 \\
Crohn's disease & 6 \\
Ischemic enterocolitis & 2 \\
Allergic purpura & 1 \\
Helicobacter pylori infection & 1 \\
Abdominal neoplasms & 1 \\
Hypogammaglobulinemia & 1 \\
Small intestinal stromal tumor & 1 \\
Peutz-Jeghers syndrome & 1 \\
\hline
\end{tabular}

\section{Histopathology and Immunohistochemical analysis}

Biopsy samples from the terminal ileum were collected from all patients with NLH, and the histological examination revealed that the nodules consisted of mass lymphoid follicles in the lamina propria and submucosa of the terminal ileum. The hyperplastic lymphoid follicles varied in size. The follicles contained mitotically active germinal centers surrounded by well-defined lymphocyte mantles (Figure 1C). At high magnification, the lymphocytes had similar size without abnormal fission and atypia, and the interfollicular areas were populated by numerous mononuclear lymphocytes (Figure 1D). Immunohistochemical staining further showed the follicles composed predominantly of $\mathrm{CD}^{2} 0^{+} \mathrm{B}$ cells. CD20 is an activated glycosylated phosphoprotein expressed on the surface of $B$ cells. As one of the transmembrane proteins, $\mathrm{CD} 79 \alpha$ forms a heterodimer with $C D 79 \beta$ on the surface of B cells. Apart from the marker of B cells, CD5 and CD3 are known as useful markers for $\mathrm{T}$ cells. The lymphoid tissues were positive for CD20 (Figure 2A) and CD79a (Figure 2B), with $\mathrm{CD}^{+} \mathrm{CD}^{+}$or $\mathrm{CD}^{-} \mathrm{CD}^{+} \mathrm{T}$ cells in the interfollicular areas (Figure $2 \mathrm{C}$ and D). CD10 is expressed by $\mathrm{B}$ cells and lymph node germinal centers. We found that the majority of cells in the germinal center were positive for CD10 (Figure 2E), but negative for Bcl-2 which is specifically considered as an important anti-apoptotic protein (Figure 2F). We also found that cells in the germinal center proliferated actively and the percentage of germinal center Ki-67 positive cells was about 70\% (Figure 2G), since $\mathrm{Ki}-67$ is a nuclear protein associated with cellular proliferation. In addition, no significant differences were observed in the comparison of the features of lymphoid follicles between NLH and NLH with Crohn's disease (Table 5).
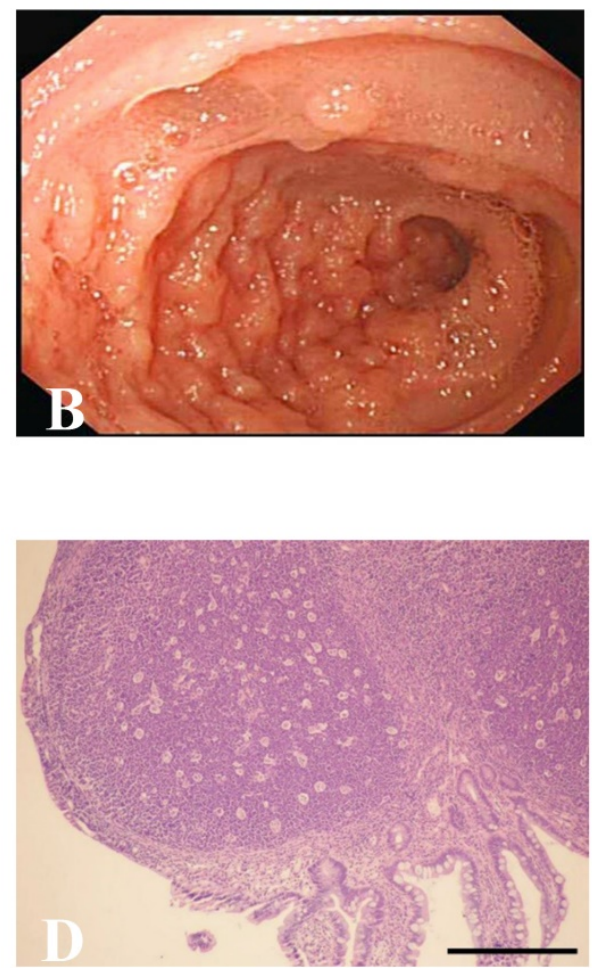

Figure 1. Ileocolonoscopic and pathological characteristics of NLH in the terminal ileum. (A, B) Endoscopic findings of NLH in the terminal ileum from patients. (C) Hyperplasic lymphoid follicles germinal centers surrounded by well-defined lymphocyte mantles $(\times 40$, scale bar: $200 \mu \mathrm{m})$, (D) Abnormal fission and atypia cells were not present at high magnification $(\times 100$, scale bar: $200 \mu \mathrm{m})$. 

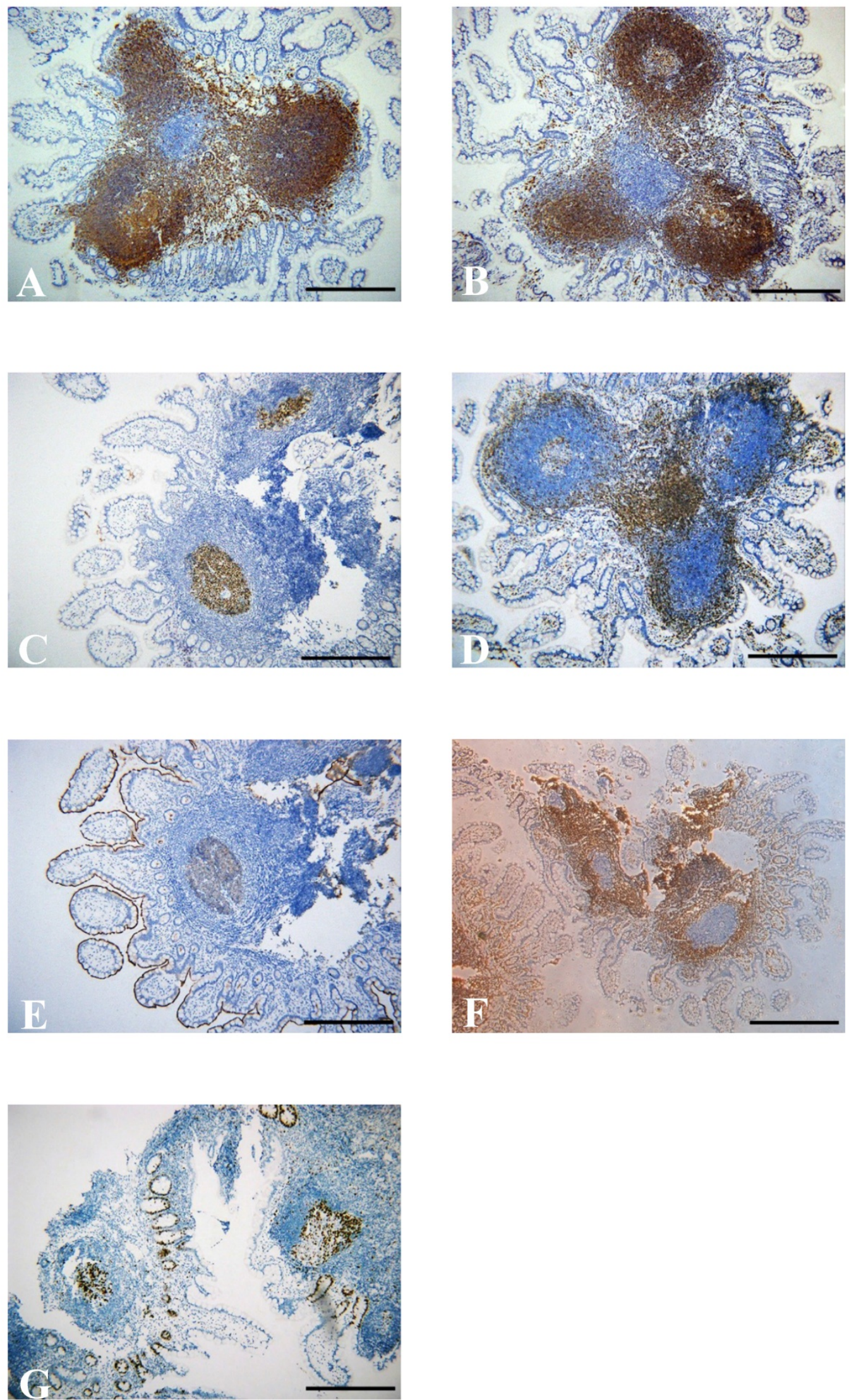

Figure 2. Immunohistochemical staining shows numerous positive cells for CD20 (A) and CD79 (B) in the germinal center. (C) CD5-positive cells in the germinal center. (D) Immunohistochemical staining for CD3-positive T cells in the interfollicular areas. Germinal center cells were positive for CDI0 (E), but negative for Bcl-2 (F). Immunohistochemical staining for $\mathrm{Ki}-67$ positive cells in germinal center $(\mathrm{G})(\times 100$, scale bar: $200 \mu \mathrm{m})$. 
Table 5. The features of lymphoid follicles between NLH and NLH with Crohn's disease

\begin{tabular}{lll}
\hline Features & $\begin{array}{l}\text { NLH with Crohn's } \\
\text { disease }\end{array}$ & NLH \\
\hline Location & $\begin{array}{l}\text { Lamina propria, } \\
\text { submucosa }\end{array}$ & $\begin{array}{l}\text { lamina propria, } \\
\text { submucosa }\end{array}$ \\
Numbers & $4-10$ & $5-12$ \\
CD20 & + & + \\
CD79 & + & + \\
CD5 & + - & + - \\
CD3 & + & + \\
CD10 & + & + \\
Bcl-2 & - & - \\
Ki-67 & $45-70 \%$ & $50-75 \%$ \\
\hline
\end{tabular}

\section{Discussion}

$\mathrm{NLH}$ is a rare benign lesion in the small intestine, and its diagnosis is based on endoscopy and histology. The hyperplastic lymphoid follicles have been found in the lamina propria and superficial submucosa, mitotically active germinal centers with well-defined lymphocytic mantles [1, 2]. In our study, we reported 65 patients with diverse morphological $\mathrm{NLH}$ through endoscopic manifestation and histological examination. As observed previously [1, $3]$, the nodules were between 2 and $5 \mathrm{~mm}$ in diameter. The histopathological findings and immunohistochemical staining were consistent with the previous literature [2,7], showing that the follicles are mainly localized in the lamina propria and submucosa of the terminal ileum. The follicles mainly consisted of $\mathrm{CD} 20^{+} \mathrm{B}$ cells, and the majority of cells in the germinal center were positive for CD10, but negative for $\mathrm{Bcl}-2$, showing benign hyperplasia. The percentage of Ki-67 positive cells in the germinal center was about $70 \%$, indicating these cells in the germinal center proliferate actively.

We reviewed the previous literature and found that 111 cases with NLH of the intestine have been reported and that NLH mainly occurs in the small intestine. The Hp infection frequently appears in NLH of the duodenum. Hypogammaglobulinemia and Giardiasis are mostly found in NLH of jejunum and ileum (Table 6). In this study, we observed that patients with NLH in the terminal ileum had 46 men and 19 women, with the range of age from 11 to 73 years. The sex ratio was similar to the previous report [11] but contrary to another study [8]. The symptom of NLH of the terminal ileum included diarrhea, abdominal pain, hematochezia, anemia and hypoproteinemia, which was different from the previous report, showing loss of weight, splenomegaly, recurrent diarrhea, respiratory tract infection, lymphadenopathy and cholelithiasis in immunodeficiency disease [3]. The link between NLH and other malignant and benign diseases has been described previously [12-16]. In our data, 36 patients with NLH had no any concomitant disorders, and six cases had the colonic Crohn's disease. It has been accepted that the disorder of gut-associated lymphoid tissue plays an important role in the pathogenesis of Crohn's disease [17-19], and NLH can exist at the remission stage and active stage of Crohn's disease. It may be attributed to dysregulation of the immune response to microbiota in the gut mucosa, leading to the development of NLH. Currently, there is no case report about the association between ischemic enterocolitis and NLH. It may be a compensatory response to intestinal mucosal inflammation or tissue injury. NLH with Hp infection has been reported in the duodenum [14]. In our study, the gastroduodenoscopy revealed duodenal ulcers in one patient with $\mathrm{Hp}$ infection, and the ileocolonoscopy showed lymphoid follicle hyperplasia in the terminal ileum. It seems no relationship between $\mathrm{Hp}$ infection and lymphoid follicle hyperplasia in the terminal ileum.

The relation between hypogammaglobulinemia, $\mathrm{NLH}$, and Giardia lamblia infection is regarded as Herman's syndrome [3], and NLH had been reported in common variable immunodeficiency (CVID) [20, 21]. However, in our data, only one patient had hypogammaglobulinemia without Giardia lamblia infection, consistent with the previous report [22]. There was no Giardia lamblia infection in our data, and the reports on Giardia lamblia infection have been found mainly in the duodenum [23, 24]. The terminal ileum associated with familial polyposis has been reported in some literature [16, 25-27]. Peutz-Jeghers syndrome is characterized by multiple small polyps in the intestinal tract, but it has a high incidence of cancer. Hence, it is important to perform surgery for resection of the lesional sites and regular follow-up colonoscopy examination. The risk of malignant transformation of NLH has been widely recognized [28]. The intestinal lymphoma has been reported in patients with NLH $[12,29]$, but the association between the small intestinal stromal tumor and NLH is unclear which needs further research. The report on extra-intestinal lymphoma with NLH is rare $[4,30]$. In addition, we found one patient had abdominal poorly-differentiated adenocarcinoma with widespread metastases.

Although NLH is a benign disease, it can also result in intestinal obstruction, intussusception, volvulus, or fatal intestinal ischemia [9]. The enteroscopy is indispensable to find NLH and determine the extent of the disease, but it is difficult to distinguish from malignant lymphomas. Thus, biopsies and histopathological examination are necessary for the diagnosis of NLH. The 
immunohistochemical features are significant in the differential diagnosis with lymphomas, and histological examination makes the differential diagnosis from polyposis.

In conclusion, ileocolonoscopy is an important step to find NLH in the terminal ileum. For individuals with abdominal pain, chronic diarrhea, hematochezia or hypoproteinemia, the colonoscopy screening is necessary (Figure 3). According to the results of immunohistochemical staining, all lymphoid follicles were reactive in nature. Hence, the disease itself generally needs no intervention, and treatment is mainly dependent on associated conditions. In our data, the enteroscopy of terminal ileum showed NLH disappeared completely in 23 idiopathic NLH cases without any intervention after 6 months follow up. The clinical symptoms can be alleviated by limiting use aspirin and non-steroidal anti-inflammatory drugs [6]. Otherwise, under several conditions such as intestinal obstruction, intussusception, and severe intestinal bleeding, local excision is curative $[7,31]$. Therefore, it is essential for excluding malignancy by biopsy and avoiding unnecessary treatment.

Table 6. Summary for localization of NLH of intestine

\begin{tabular}{|c|c|c|c|c|c|c|c|c|}
\hline & $\begin{array}{l}\text { Duodenum } \\
{[13,14,24]}\end{array}$ & $\begin{array}{l}\text { Jejunum } \\
{[3,32]}\end{array}$ & $\begin{array}{l}\text { Ileum } \\
{[1,7,16,21,25]}\end{array}$ & $\begin{array}{l}\text { Jejunum, ileum } \\
\text { [11] }\end{array}$ & $\begin{array}{l}\text { Small intestine } \\
{[2,5,8,15,22,23,29]}\end{array}$ & $\begin{array}{l}\text { Colon } \\
{[6,31]}\end{array}$ & $\begin{array}{l}\text { Colon, ileum } \\
{[9,27]}\end{array}$ & $\begin{array}{l}\text { Larger intestine, } \\
\text { small intestine }[4]\end{array}$ \\
\hline Cases & 42 & 9 & 7 & 11 & 36 & 2 & 3 & 1 \\
\hline Hypogammaglobulinemia & $1 / 42$ & $9 / 9$ & $2 / 7$ & $5 / 11$ & $3 / 36$ & & & \\
\hline Giardiasis & $2 / 42$ & $6 / 9$ & $1 / 7$ & $5 / 11$ & $19 / 36$ & & & \\
\hline Hp infection & $40 / 42$ & & & & & & & \\
\hline Familial polyposis & & & $2 / 7$ & & & & $1 / 3$ & \\
\hline CVID & & & $1 / 7$ & & $1 / 36$ & & & \\
\hline Lymphoma & & & & $2 / 11$ & $2 / 36$ & & & $1 / 1$ \\
\hline
\end{tabular}

CVID: common variable immunodeficiency

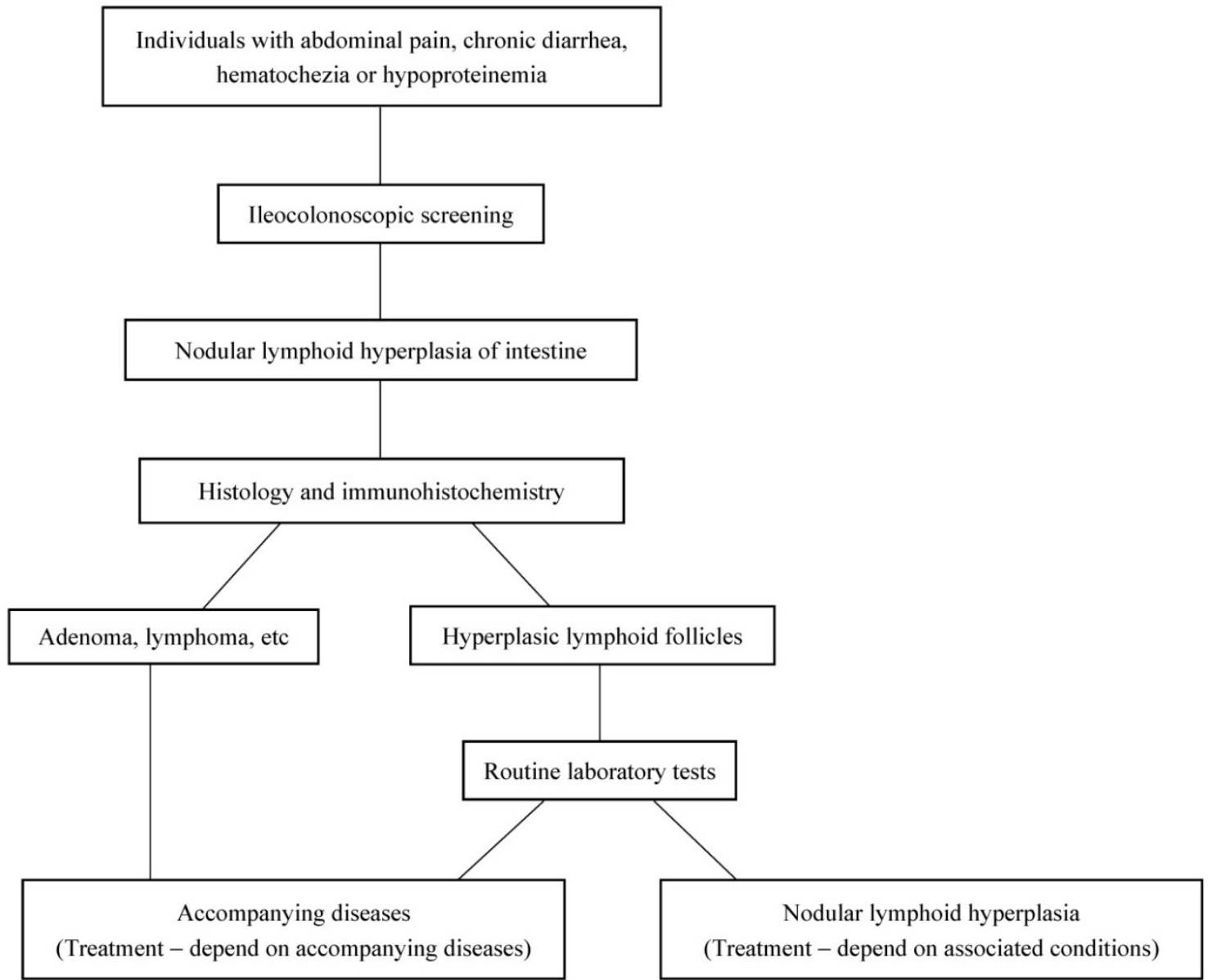

Figure 3. The diagnostic diagram for NLH in the intestine. 


\section{Abbreviations}

NLH: nodular lymphoid hyperplasia;

CRP: C-reactive protein;

ALP: alkaline phosphatase;

ESR: erythrocyte sedimentation rate;

WBC: white blood cell counts;

$\mathrm{Hb}$ : hemoglobin;

Hp: Helicobacter pylori;

CVID: common variable immunodeficiency.

\section{Acknowledgements}

The study was approved by National Natural Science Foundation of China, No. 81470822.

\section{Competing Interests}

The authors have declared that no competing interest exists.

\section{References}

1. Ranchod M, Lewin KJ, Dorfman RF. Lymphoid hyperplasia of the gastrointestinal tract. American Journal of Surgical Pathology. 1978; 2: 383-400.

2. Rambaud JC, Saint-Louvent PD, Marti R, Galian A, Mason DY, Wassef M, et al. Diffuse follicular lymphoid hyperplasia of the small intestine without primary immunoglobulin deficiency. American Journal of Medicine. 1982; 73: $125-32$.

3. Hermans PE, Huizenga KA, Hoffman HN, Jr BA, Markowitz H. Dysgammaglobulinemia associated with nodular lymphoid hyperplasia of small intestine. American Journal of Medicine 1966; 40: 78-89.

4. Jonsson OT, Birgisson S, Reykdal S. Resolution of nodular lymphoid hyperplasia of the gastrointestinal tract following chemotherapy for extraintestinal lymphoma. Digestive Diseases \& Sciences. 2002; 47: 2463-5.

5. Garg V, Lipka S, Rizvon K, Singh J, Rashid S, Mustacchia P. Diffuse nodular lymphoid hyperplasia of intestine in selective IgG 2 subclass deficiency, autoimmune thyroiditis, and autoimmune hemolytic anemia: case report and literature review. Journal of Gastrointestinal \& Liver Diseases Jgld. 2012; 21: $431-4$.

6. Schwartz DC, Cole CE, Sun Y, Jacoby RF. Diffuse nodular lymphoid hyperplasia of the colon: polyposis syndrome or normal variant? Gastrointestinal Endoscopy. 2003; 58: 630-2.

7. Mukhopadhyay S, Harbol T, Floyd FD, Sidhu JS. Polypoid Nodular Lymphoid Hyperplasia of the Terminal Ileum. Archives of Pathology \& Laboratory Medicine. 2004; 128: 1186-7.

8. Rubio-Tapia A, Hernéndez-Calleros J, Trinidad-Hernández S, Uscanga L. Clinical characteristics of a group of adults with nodular lymphoid hyperplasia: A single center experience. World Journal of Gastroenterology. 2006; 12: 1945-8.

9. Coulibaly B, Piercecchi-Marti MD, Bartoli C, Liprandi A, Sanvoisin A, Leonetti G. Benign lymphoid polyposis: two diffuse cases leading to fatal intestinal ischemia in children. Pediatrics international : official journal of the Japan Pediatric Society. 2009; 51: 428-31.

10. Albuquerque A. Nodular lymphoid hyperplasia in the gastrointestinal tract in adult patients: A review. World journal of gastrointestinal endoscopy. 2014; 6: 534-40.

11. Canto J, Arista J, Hernández J. Nodular lymphoid hyperplasia of the intestine. Clinico-pathologic characteristics in 11 cases. Revista de investigación clínica: organo del Hospital de Enfermedades de la Nutrición. 1990; 42: 198-203.

12. Matuchansky C, Touchard G, Lemaire M, Babin P, Demeocq F, Fonck Y, et al. Malignant lymphoma of the small bowel associated with diffuse nodular lymphoid hyperplasia. New England Journal of Medicine. 1985; 313: 166-71.

13. Baran B, Gulluoglu M, Akyuz F. Nodular lymphoid hyperplasia of duodenum caused by giardiasis. Clinical gastroenterology and hepatology : the official clinical practice journal of the American Gastroenterological Association. 2013; 11: A22.

14. Khuroo MS, Khuroo NS, Khuroo MS. Diffuse duodenal nodular lymphoid hyperplasia: a large cohort of patients etiologically related to Helicobacter pylori infection. BMC gastroenterology. 2011; 11: 36.

15. Ward H, Jalan KN, Maitra TK, Agarwal SK, Mahalanabis D. Small intestinal nodular lymphoid hyperplasia in patients with giardiasis and normal serum immunoglobulins. Gut The Journal of the British Society of Gastroenterology. 1983; 24: 120-6.

16. Dorazio RA, Jr WT. Lymphoid hyperplasia of the terminal ileum associated with familial polyposis coli. Annals of Surgery. 1970; 171: 300-2.
17. Hizawa K, Iida M, Aoyagi K, Fujishima M. The significance of colonic mucosal lymphoid hyperplasia and aphthoid ulcers in crohn's disease. Clinical Radiology. 1996; 51: 706-8.

18. Fujimura Y, Kamoi R, Iida M. Pathogenesis of aphthoid ulcers in Crohn's disease: correlative findings by magnifying colonoscopy, electron microscopy, and immunohistochemistry. Gut. 1996; 38: 724-32.

19. Chiba M, Komatsu M, lizuka M, Masamune O, Hoshina S, Kong M. Microbiology of the intestinal lymph follicle: a clue to elucidate causative microbial agent(s) in Crohn's disease. Medical Hypotheses. 1998; 51: 421-7.

20. Khodadad A, Aghamohammadi A, Parvaneh N, Rezaei N, Mahjoob F, Bashashati M, et al. Gastrointestinal manifestations in patients with common variable immunodeficiency. Digestive Diseases \& Sciences. 2007; 52: 2977-83.

21. Said-Criado I, Gil-Aguado A. Nodular lymphoid hyperplasia in common variable immunodeficiency. Lancet. 2014; 383: e2

22. Postgate A, Despott E, Talbot I, Phillips R, Aylwin A, Fraser C. An unusual cause of diarrhea: diffuse intestinal nodular lymphoid hyperplasia in association with selective immunoglobulin A deficiency (with video). Gastrointestinal Endoscopy. 2009; 70: 168-9; discussion 9.

23. Olmez S, Aslan M, Yavuz A, Bulut G, Dulger AC. Diffuse nodular lymphoid hyperplasia of the small bowel associated with common variable immunodeficiency and giardiasis: a rare case report. Wiener klinische Wochenschrift. 2014; 126: 294-7.

24. de Weerth A, Gocht A, Seewald S, Brand B, van Lunzen J, Seitz U, et al. Duodenal nodular lymphoid hyperplasia caused by giardiasis infection in a patient who is immunodeficient. Gastrointestinal Endoscopy. 2002; 55: 605-7.

25. Jr SL, Fitts CT. Lymphoid polyposis associated with familial polyposis and Gardner's syndrome. Annals of Surgery. 1974; 180: 319-22.

26. Thomford NR, Greenberger NJ. Lymphoid polyps of the ileum associated with Gardner's syndrome. Archives of Surgery. 1968; 96: 289-91.

27. Venkitachalam PS, Hirsch E, Elguezabal A, Littman L. Multiple lymphoid polyposis and familial polyposis of the colon: A Genetic relationship. Diseases of the Colon \& Rectum. 1978; 21: 336-41.

28. Ryan JC. Premalignant conditions of the small intestine. Seminars in Gastrointestinal Disease. 1996; 7: 88-93.

29. Castellano G, Moreno D, Galvao O, Ballestín C, Colina F, Mollejo M, et al. Malignant lymphoma of jejunum with common variable hypogammaglobulinemia and diffuse nodular hyperplasia of the small intestine. A case study and literature review. Journal of Clinical Gastroenterology. 1992; 15: 128-35.

30. Monsanto P, Lérias C, Almeida N, Lopes S, Cabral JE, Figueiredo P, et al. Intestinal nodular lymphoid hyperplasia and extraintestinal lymphoma--a rare association. Acta gastro-enterologica Belgica. 2012; 75: 260-2.

31. Ersoy E, Gündoğdu H, Uğraş NS, Aktimur R. A case of diffuse nodular lymphoid hyperplasia. Turkish Journal of Gastroenterology the Official Journal of Turkish Society of Gastroenterology. 2008; 19: 268-70.

32. Ajdukiewicz AB, Youngs GR, Bouchier IAD. Nodular lymphoid hyperplasia with hypogammaglobulinemia. Gut. 1972; 13: 589-95. 